DOI: https://doi.org/10.47405/mjssh.v6i11.1176

\begin{tabular}{|c|c|}
\hline 4.581 & Malaysian Journal of Social Sciences and Humanities (MJSSH) \\
\hline $\begin{array}{l}\text { Malaysian Journal of } \\
\text { Social cciences and }\end{array}$ & Volume 6, Issue 11, November 2021 \\
\hline (MJ-SSH) & e-ISSN : 2504-8562 \\
\hline & $\begin{array}{l}\text { Journal home page: } \\
\text { www.msocialsciences.com }\end{array}$ \\
\hline
\end{tabular}

\title{
Gratitude and Its Relationship with Students' Psychological Well-Being and Happiness
}

\author{
Dorkas Ping Bilong1, Ida Juliana Hutasuhut', Mohamad Azhari Abu Bakar', Nurul Wardhani \\ 1Faculty of Cognitive Sciences and Human Development, University Malaysia Sarawak (UNIMAS), \\ Sarawak, Malaysia \\ 2Faculty of Psychology, University of Padjadjaran, Bandung, Indonesia
}

Correspondence: Ida Juliana Hutasuhut (hijuliana@unimas.my)

\begin{abstract}
This study examines gratitude among undergraduate students of a public university in Malaysia and its relationship with psychological well-being and happiness. This study took 149 samples randomly from 235 undergraduate students who were asked to participate in answering Gratitude Questionnaire-6, Ryff's Scale of Psychological Well Being, and Subjective Happiness Scale. Correlation analysis shows a positive relationship between gratitude and students' psychological well-being and happiness. This study supports the previous studies that practicing gratitude is a positive way to enhance students' healthy psychological well-being and happiness in their life. This study recommends the university management to take consideration to cultivate gratitude practice embedded in the curriculum or in the extracurricular activities.
\end{abstract}

Keywords: gratitude, psychological well-being, happiness

\section{Introduction}

Numerous studies suggest that university students are one of the most vulnerable populations to developing mental health-related problems since it is emotionally and intellectually demanding compared to other stages of educations (Auerbach et al., 2018; Bruffaerts et al., 2018; Cleofas, 2020; Saleem, Mahmood, \& Naz, 2013; Zivin, Eisenberg, Gollust, \& Golberstein, 2009). University students face various challenges and pressures, such as physical, social, financial, and emotional difficulties during their studies. Students are prone to feel stress due to their assignments, exams, and relationships with others, which can cause low psychological well-being and happiness. Not to mention, the current situation of the pandemic that forces them to dramatically change the learning method from face-toface learning to online learning might contribute to lower psychological well-being and happiness among students. It has to do with the fact that some students may not have a conducive learning environment while studying from home, making it more stressful for them to do online learning. On this account, there is a need to advocate a method to obtain healthy psychological well-being and happiness for students. One approach that is being increasingly highlighted by both scholars and practitioners is gratitude, an approach from positive psychology.

Gratitude is the feeling of thankfulness towards God, self, other people, and the things that happen around us (Behzadipour, Sadeghi, \& Sepahmansour, 2018; Emmons \& McCullough, 2003). According to Kumari and Madnawat (2016), gratitude is the appreciation of meaningful and valuable things and 
represents a general state of gratefulness. It is well-known that gratitude can result in mental prosperity, overall health, happiness, and more fulfilling personal relationships (Emmons \& Crumpler, 2000). Watkins, Woodward, Stone, and Kolts (2003) found a significant strong relationship between dispositional gratitude and various measure of psychological well-being and happiness in their study. Other empirical studies involving teenagers as well as university students also indicated a correlation between gratitude and overall well-being (Behzadipour, Sadeghi, \& Sepahmansour, 2018; Kumari \& Madnawat, 2016; Robustelli \& Whisman, 2018; Sapmaz, Yıldırım, Topçuoğlu, Nalbant, \& Sizır, 2016; Yildirim \& Alanazi, 2018). Moreover, gratitude interventions can improve mood and promote happiness by enhancing experiences of positive events (Watkins et al., 2003). These previous studies showed that there are many benefits of gratitude in students, namely physical, mental health, and social. Therefore, gratitude practices can be expected as an effective way to ensure students feel grateful despite the challenges from the stressful environment, especially during this pandemic.

The studies on gratitude have been conducted most often in other foreign countries, and very little had done in Malaysia. The findings may and may not be parallel to earlier studies due to cultural differences and other factors. Hence, there is a need to investigate the relationship between gratitude and psychological well-being and happiness among students in Malaysia. The research hypothesis for this study is $\mathrm{H}_{01}$ : there is a relationship between gratitude and students' psychological well-being, and $\mathrm{H}_{02}$ : there is a relationship between gratitude and students' happiness.

\section{Literature Review}

\section{Gratitude, Well-being, and Happiness}

The word gratitude generally means graciousness, grace, or gratitude (Yoo, 2020). Gratitude is the sense of a positive experience and feeling appreciated through the actions of others (Emmons \& McCullough, 2003). People that interpret their experience as gratitude will experience high positive emotions, lower levels of stress, and healthier relationships, where all of these are components of psychological well-being (Duckworth, Steen, \& Seligman, 2005; Watkins, Cruz, Holben, \& Kolts, 2008; Wilson, 2016; Wood, Joseph, \& Maltby, 2009). Some researchers claim that people with high gratitude have a lower threshold for experiencing gratefulness and tend to stay positive and experience happiness in situations where they receive kindness (Roberts, 2004; Watkins, 2004). People with a high level of gratitude feel more grateful after experiencing positive emotions and gratitude several times a day than a lower level of gratitude people.

Gratitude is considered a personal trait as well as an emotional state. The emotional state of gratitude is the positive emotions experienced due to others' acts of generosity or kindness (Emmons, 2004; Rash, Matsuba, \& Prkachin, 2011). Roberts (2004) defines these experiences as episodic gratitude, where people undergo intense, acute, and short physiological changes. The feeling of gratitude implies a subjective cognitive assessment of the situation and a physiological change. From the characteristic viewpoint, gratitude is recognized as a virtue or trait of people that differ in frequency, intensity, and extent (McCullough, Emmons, \& Tsang, 2002).

Gratitude also positively impacts cognitive function, as Brown and Wong (2017) stated that gratitude releases us from toxic emotions and has a lasting effect on our brains. Expressing gratitude makes the brain releases serotonin and dopamine, which give a good feeling to people (Chowdhury, $\mathrm{n}, \mathrm{d}$.). These neurotransmitters enhance mood and instantly make people feel happier. Additionally, gratitude involves realizing and appreciating the cause that makes them feel grateful. Admitting there are numerous things to be thankful for in life can increase psychological well-being and happiness in individuals (Behzadipour, Sadeghi, \& Sepahmansour, 2018). Besides, according to Kardas, Zekeriya, Eskisu, and Gelibolu (2019), gratitude is conceptualized and measured based on perspectives including having a positive social relationship, feeling satisfied from small things, recognizing the contributions of others, focusing on the positive things, and expressing gratitude. All in all, practicing gratitude can change our perspective on people and things that happen in our lives into something positive. 
A study conducted in Iran by Behzadipour, Sadeghi, and Sepahmansour (2018) found that gratitude training improves psychological well-being and happiness. Gratitude can increase one's psychological well-being by enhancing happy experiences, improving dealing with negative occurrences, and expanding social networks from individuals (Emmons \& McCullough, 2003; Rash, Matsuba, \& Prkachin, 2011). Practicing gratitude had positive influences on all aspects of psychological wellbeing and happiness. Stoerkel (2020) identified that researchers in positive psychology have discovered that thankfulness and happiness are always significantly associated. For instance, practicing writing a gratitude letter notably affects a person's happiness more than other interventions (Christanto et al., 2017), and writing a thanksgiving note has been shown to improve happiness and decrease sadness in both teenagers and adults (Toepfer, Cichy, \& Peters, 2012). Froh, Kashdan, Ozimkowski, and Miller (2009) also found that students who wrote gratitude letters for five days were happier and more motivated than students who wrote things that happened in a day on a daily journal.

Moreover, psychological well-being is found strongly related to life satisfaction and happiness based on a study conducted by Yildirim and Alanazi (2018). Happiness is a state of being happy and can easily be acquired through minimal cognitive and behavioral approaches that everyone can use in their lives (Layous \& Lyubomirsky, 2014; Sin \& Lyubomirsky, 2009). Expressing gratitude generates happiness, experience positive emotions, enhance health, overcome hardship, and form and sustain strong relationships, all of which led to feeling happy and less time for negative thoughts (Stoerkel, 2020). Layous and Lyubomirsky (2014) proposed the practice of Positive Activity Interventions (PAIs) to obtain happiness, such as writing gratitude journaling, doing kindness, meditating, counting blessings, optimism practice, and many more. These exercises can encourage positive thoughts, behaviors, and feelings in individuals who practice them. Toepfer, Cichy, and Peters (2012) believe that thankfulness plays a significant role as a potential agent for changing one's degree of happiness and subjective well-being simply by expressing gratitude itself. Therefore, gratitude has a positive relationship with both psychological well-being and happiness in general.

Furthermore, studies on gratitude have shown a correlation to positive social relationships, spiritualityenhancing qualities, and pro-social constructs that are likely to improve one's overall well-being and life satisfaction (Kumari \& Madnawat, 2016). Gratitude is also highly valued in many cultures and communities since it can enhance social bonds and even have a moral consequence (Yoo, 2020). In terms of social relationships, many studies on gratitude intervention have been proven effective at improving relationships with people (Dioszeghy, 2018; Jin, Line, \& Yoon, 2017; Kim \& Qu, 2020). Practicing gratitude in relationships with others such as family, loved ones, or professional relationships was discovered to produce a happy and productive relationship.

\section{Theories of Happiness}

Authentic happiness theory synthesizes all three types of happiness, which are the pleasant life (hedonism theory), the good life (desire theory), and the meaningful life (objective list theory) collectively meet all criteria of happiness (Seligman \& Royzman, 2003). Firstly, the hedonism theory believes that happiness is a matter of subjective feelings. A happy life will maximize feelings of happiness and minimize feelings of pain (Seligman \& Royzman, 2003). Thus, based on hedonism theory, a happy person experiences more pleasure than painful experiences in their life. In contrast, desire theory indicates that happiness is about getting what you want (Seligman \& Royzman, 2003). The second theory of desire believes that accomplishing a desire promotes happiness, irrespective of the degree of satisfaction or dissatisfaction. The third theory of the objective list indicates that happiness is more about accomplishing or achieving valuable things in the world. It believes that happiness comprises a human life that fulfills certain things from a list of meaningful activities, such as professional achievements, education and knowledge, family life, physical comfort, beauty, and love (Seligman \& Royzman, 2003). In conclusion, authentic happiness theory comprises all three types of happiness (hedonism, desire, and objective list) as one theory. Therefore, to be happy, we must feel pleasure, get what we want, and accomplish our objective in life. 


\section{Methodology}

This study is correlational research examining gratitude and its relationship with psychological wellbeing and happiness. The data was collected through distributing the questionnaire using the Google Form to all the population totaling 235 students, and the returned questionnaire is 149 . The Google Form is utilized to collect data due to the restriction caused by the pandemic. The survey uses the Gratitude Questionnaire-6 (GQ-6), Ryff's Scale of Psychological Well Being (RSPWB), and Subjective Happiness Scale (SHS) to measure the variables.

GQ-6 was used to measure levels of gratitude and consists of 6-items. It uses Likert scales ranging from 1 (strongly disagree) to 7 (strongly agree) (McCullough, Emmons, \& Tsang, 2002). According to Gray, Emmons, and Morrison (2001), individuals who score above the median on the GQ-6 report feeling more thankful, appreciative, and grateful than individuals who score below the median. The Cronbach's alpha estimates for the 6-items totals have ranged from .76 to .84. GQ-6 also has validity with the range of $.551-.807$ with the value of $\alpha=.768$ (Christanto et al., 2017). Additionally, RSPWB was used to measure students' psychological well-being. It has 42 -items and is based on a Likert scale from 1 (completely disagree) to 7 (completely agree). RSPWB measures six dimensions of psychological well-being (autonomy, environmental mastery, personal growth, positive relations with others, purpose in life, and self-acceptance), where each consists of seven items. For each dimension, a high score indicates that the respondent has a mastery of that area in their life, while a low score shows that the respondent struggles to feel comfortable with that particular concept. Ryff and colleagues have not published global cut-offs indicating what classifies as a low or high score on these scales. Therefore, researchers might classify the lower and upper quartiles (25\%) of responses as low and high, assuming a normal sample distribution. According to Bayani, Koocheky, and Bayani (2008), RSPWB had a test-retest reliability coefficient of 0.82. The self-acceptance, positive relationships with others, autonomy, environmental mastery, purpose in life, and personal growth were statistically significant subscales of $0.71,0.77,0.78,0.77,0.70$, and 0.78 , respectively. Lastly, the SHS questionnaire was used to measure the students' happiness levels (Lyubomirsky \& Lepper, 1999). SHS is a 4-items, 7-point scale that measures an individual global subjective happiness. The average score for the general population varies according to gender, age, and other personal characteristics. However, it usually ranges between 4.5 and 5.5. College students tend to score lower (averaging a bit below 5) than working adults and older, retired people (who average 5.6). The reliability of SHS is $\alpha=0.77$ (Behzadipour, Sadeghi, \& Sepahmansour, 2018).

Overall, all the questionnaires used have good reliability and validity to measure each of the variables. Data analysis uses Pearson Correlations to measure the relationship between gratitude and psychological well-being and gratitude and happiness.

\section{Result and Discussion}

The descriptive statistics show the mean value for students' gratitude was 32.9933 ( $\mathrm{SD}=5.56473$ ) (Table 1). This score indicates that, in general, students have high scores of gratitude since the scores are above the median score. Based on the data, most students have a lot to be thankful for in life, including appreciating people, events, and situations in their life. Thus, it can indicate that students understand what gratitude is and practice it in their life. On the other hand, the descriptive statistics show that the mean value for students' psychological well-being was 193.7517 (SD = 28.28544). This score indicates that most students have good psychological well-being since the mean average of the score is average. Lastly, the descriptive statistics show that the mean value for happiness was 19.3624 $(\mathrm{SD}=4.56665)$. The score indicates that, in general, students are happy, considering the mean score is around the average range score for students. From the findings, it is understood that most students consider themselves happy people and think that they are usually feeling happy daily. To conclude, the study finds that students understand and practice gratitude in their life and in general, they have average psychological well-being, and most of them are happy students. 
DOI: https://doi.org/10.47405/mjssh.v6i11.1176

Table 1: Mean and standard deviation of the variables

\begin{tabular}{llll}
\hline Variables & N & Mean & Standard deviation \\
\hline Gratitude & 149 & 32.9933 & 5.56473 \\
Psychological well-being & 149 & 193.7517 & 28.28544 \\
Happiness & 149 & 19.3624 & 4.56665 \\
\hline
\end{tabular}

The present study has shown a significant strong positive relationship between gratitude and students' psychological well-being (as shown in Table 2). It indicates that a higher level of gratitude reflects a higher level of psychological well-being in students. The result adds further empirical support to previous studies on the relationship between gratitude and psychological well-being (Aghababaei, Błachnio, \& Aminikhoo, 2018; Behzadipour, Sadeghi, \& Sepahmansour, 2018; Hemarajarajeswari \& Gupta, 2021; Kumari \& Madnawat, 2016; Tian, Huebner, \& Du, 2016). Based on the present study, the higher the score on gratitude, the higher the score on overall psychological well-being in students. It also means that the more someone appreciates people around them, things surrounding them, and themselves, the better their psychological well-being is.

Table 2: Correlations between gratitude and psychological well-being

\begin{tabular}{llll}
\hline & & Gratitude & Psychological well-being \\
\hline Gratitude & Pearson Correlation & 1 & $.651^{* *}$ \\
& Sig. (2-tailed) & & .000 \\
& $\mathrm{~N}$ & 149 & 149 \\
Psychological well-being & Pearson Correlation & $.651^{* *}$ & 1 \\
& Sig. (2-tailed) & .000 & \\
& $\mathrm{~N}$ & 149 & 149 \\
\hline
\end{tabular}

**. Correlation is significant at the 0.01 level (2-tailed).

According to Loi and $\mathrm{Ng}$ (2021), fostering a grateful mindset could enhance well-being. Gratitude influences several positive changes in the emotional state, hence boosting the levels of psychological well-being of the person (Măirean, Turliuc, \& Arghire, 2019). Gratitude also contributes to well-being by increasing the retrieval of positive memories or experiences of the individuals (Sheldon, Kashdan, \& Steger, 2010). Therefore, grateful people benefit from a pleasant memory of a positive event in their lives.

Moreover, gratitude is the appreciation of various perspectives, such as feeling satisfied from small things, recognizing help from others, being optimistic, having a positive relationship with others, and expressing gratitude (Kardas et al., 2019). Doing all these things will eventually increase students' psychological well-being. Nevertheless, gratitude also benefits people by bringing relationships closer with others (Elosúa, 2015). Thus, students can also benefit from having a good relationship with others alongside having good well-being. In the light of the finding, students can practice gratitude in their life to keep their psychological well-being healthy. Overall, this study provides further empirical support to the assumption that a high level of trait gratitude is positively associated with a high level of psychological well-being.

Likewise, the present study has also shown that gratitude has a significant strong positive relationship with the students' happiness (as shown in Table 3). It indicates that a high level of gratitude reflects a high level of happiness in students. 
DOI: https://doi.org/10.47405/mjssh.v6i11.1176

Table 3: Correlations between gratitude and happiness

\begin{tabular}{llll}
\hline & & Gratitude & Happiness \\
\hline Gratitude & Pearson Correlation & 1 & $.604^{* *}$ \\
& Sig. (2-tailed) & & .000 \\
Happiness & $\mathrm{N}$ & 149 & 149 \\
& Pearson Correlation & $.604^{* *}$ & 1 \\
& Sig. (2-tailed) & .000 & 149 \\
\hline
\end{tabular}

**. Correlation is significant at the 0.01 level (2-tailed).

The current study also shows that gratitude has a strong positive relationship with happiness. This result is equivalent to previous studies on the association of gratitude and students' happiness (Aghababaei, Błachnio, \& Aminikhoo, 2018; Behzadipour, Sadeghi, \& Sepahmansour, 2018; Kausar, 2018; Loi \& Ng, 2021; Rajan \& Easvaradoss 2012; Sapmaz et al., 2016). Similarly, Chavan, Deshmukh, and Singh's (2017) study reported that gratitude is one of the best predictors of happiness. Also, according to Singh, Salve, and Shejwal (2017), the practice of gratitude in daily life can make life happier and more satisfying. Expressing gratitude makes the brain releases serotonin and dopamine, which enhance mood and give a good feeling to people, making people feel happier (Chowdhury, n, d.). Likewise, gratitude creates positive emotions, such as joy, contentment, love, and satisfaction, and decreases negative emotions like sadness, anger, and anxiety (Greenberg, 2015). Thus, people pay more attention to positive emotions than the negative ones when they feel more grateful, hence generating happiness.

The current study offers empirical support to the hypothesis that gratitude correlates with happiness. The result is relevant to Alsukah and Basha's (2021) study, where gratitude can improve happiness levels in university students. Authentic happiness theory highlights the importance of all types of happiness to feel happy in life, and gratitude practices complement it by providing the pleasure, desire, and meaningful elements to create happiness for individuals. To be more specific, expressing gratitude allow students to feel the contentment of returning the favor of others, being able to fulfill the desire to express gratitude, and have meaningful goals. All of this combined and generates authentic happiness in students. Hence, being grateful and expressing gratitude are directly linked to generating happiness as well as healthy psychological well-being. Students should understand the significance of gratitude practice towards their well-being and begin practicing gratitude in their lives.

Overall, apart from having a positive relationship with psychological well-being, gratitude also has a positive relationship with happiness. It could indicate that gratitude has an essential role in students' mental health. Thus, if a person often practices gratitude in their everyday lives, it will enable them to sustain healthy psychological well-being and happiness in life. Gratitude should be cultivated and encouraged as being the culture or climate of a university, as the previous study found the importance of context to individual learning (Hutasuhut, Adruce \& Jonathan, 2021). Universities may promote gratitude practice by doing a campaign or various activities that involves gratitude, as gratitude has positive relationship with resilience and academic performance (Nailah Najwa, Hutasuhut, Mohamad Azhari, \& Nurul Wardhani, 2021). Gratitude intervention can be incorporated in the curriculum or in the extracurricular activities.

\section{Conclusion and Recommendation}

This study proved that gratitude has a strong positive relationship with both psychological well-being and happiness in students. Gratitude practices can benefit students to feel grateful to themselves, others, and situations and eventually produce healthy psychological well-being and happiness. Instead of being stressed while studying, students can practice gratitude in their life and have healthy psychological well-being and a higher happiness level. On top of that, they may utilize gratitude practice as a coping mechanism for their mental health. Gratitude practices can help students perceive things positively, especially when dealing with stressful environments or experiences as university 
students. The importance of gratitude during this time of pandemics deems crucial for students to stay optimistic. More importantly, the result of this study is practically helpful for students in schools and universities. It is because gratitude practice can ensure students have healthy psychological well-being and happiness despite the adversity experience at school or university. Hence, universities and schools should encourage students to express more gratitude in their life for their psychological well-being and happiness. They can promote gratitude practices through various means, namely campaigns, talks, during lectures et cetera. In addition, the findings of this study provide empirical support on the implementation of psychological interventions designed to improve students' overall well-being and happiness. It is recommended for future research to focus on gratitude-based intervention studies to develop an efficient method to enhance students' psychological well-being and happiness. Future research should also be conducted in a larger population and a different educational background to increase the generalizability of the findings.

\section{References}

Aghababaei, N., Błachnio, A., \& Aminikhoo, M. (2018). The relations of gratitude to religiosity, wellbeing, and personality. Mental Health, Religion \& Culture, 21(4), 408-417.

Alsukah, A. I., \& Basha, S. E. (2021). The relative contribution of mindfulness and gratitude in predicting happiness among university students. Journal of Educational and Social Research, 11(4), 314-314.

Auerbach, R. P., Mortier, P., Bruffaerts, R., Alonso, J., Benjet, C., Cuijpers, P., Demyttenaere, K., Ebert, D. D., Green, J. G., Hasking, P., Murray, E., Nock, M. K., Pinder-Amaker, S., Sampson, N. A., Stein, D. J., Vilagut, G., Zaslavsky, A. M., Kessler, R. C., \& WHO WMH-ICS Collaborators. (2018). WHO world mental health surveys international college student project: Prevalence and distribution of mental disorders. Journal of Abnormal Psychology, 127(7), 623638. Retrieved from https://doi.org/10.1037/abn0000362

Bayani, A. A., Koocheky, A. M., \& Bayani, A. (2008). Reliability and validity of Ryff's psychological well-being scales. Iranian Journal of Psychiatry and Clinical Psychology, 14, 146-151.

Behzadipour, S., Sadeghi, A., \& Sepahmansour, M. (2018). A study on the effect of gratitude on happiness and well-being. Biquarterly Iranian Journal of Health Psychology, 1(2), 65-72.

Brown, J., \& Wong, J. (2017). How gratitude changes you and your brain. Retrieved from https://greatergood.berkeley.edu/article/item/how_gratitude_changes_you_and_your_brain

Bruffaerts, R., Mortier, P., Kiekens, G., Auerbach, R. P., Cuijpers, P., Demyttenaere, K., Green, J.G., Nock, M.K., \& Kessler, R. C. (2018). Mental health problems in college freshmen: Prevalence and academic functioning. Journal of Affective Disorders, 225, 97-103.

Chavan, S., Deshmukh, J., \& Singh, B. (2017). Role of mindfulness, belief in personal control, gratitude on happiness among college students. Indian Journal of Health \& Wellbeing, 8(10), 1184-1186.

Chowdhury, M. R. (n, d.). The neuroscience of gratitude and how it affects anxiety \& grief. Retrieved from https://positivepsychology.com/neuroscience-of-gratitude/

Christanto, S. A., Brenda, D., Assisiansi, C., Pangestu, M. J., Sarita, I., \& Sulistiani, V. (2017). Gratitude letter: An effort to increase subjective well-being in college. ANIMA Indonesian Psychological Journal, 32(3), 158-168.

Cleofas, J. V. (2020). Student involvement, mental health, and quality of life of college students in a selected university in Manila, Philippines. International Journal of Adolescence and Youth, 25(1), 435-447.

Dioszeghy, B. D. (2018). Gratitude in relationships: A study on gratitude, attachment, and relationship satisfaction. Educational Specialist, 2009-2019. 130. Retrieved from https://commons.lib.jmu.edu/edspec201019/130

Duckworth, A. L, Steen, T. A., \& Seligman, M. E. (2005). Positive psychology in clinical practice. Annu. Rev. Clin. Psychol., 1, 629-651.

Elosúa, M. R. (2015). The influence of gratitude in physical, psychological, and spiritual wellbeing. Journal of Spirituality in Mental Health, 17(2), 110-118.

Emmons, R. A., \& Crumpler, C. A. (2000). Gratitude as a human strength: Appraising the evidence. Journal of social and Clinical Psychology, 19(1), 56-69. 
Emmons, R.A. (2004). The psychology of gratitude. In R.A. Emmons \& M.E. McCullough (Eds.), The psychology of gratitude (pp. 3-16). New York: Oxford University Press.

Emmons, R.A., \& McCullough, M. E. (2003). Counting blessings versus burdens: An experimental investigation of gratitude and subjective well-being in daily life. J. Pers. Soc. Psychol, 84, 377389.

Froh, J. J., Kashdan, T. B., Ozimkowski, K. M., \& Miller, N. (2009). Who benefits the most from a gratitude intervention in children and adolescents? Examining positive affect as a moderator. The Journal of Positive Psychology, 4(5), 408-422.

Gray, S. A., Emmons, R. A., \& Morrison, A. (2001). Distinguishing gratitude from indebtedness in affect and action tendencies. Poster presented at the annual meeting of the American Psychological Association, San Francisco, CA.

Greenberg, M. (2015). How gratitude leads to a happier life. Retrieved from https://www.psychologytoday.com/us/blog/the-mindful-self-express/201511/how-gratitudeleads-happier-life

Hemarajarajeswari, J., \& Gupta, P. K. (2021). Gratitude, psychological well-being, and happiness among college students: a correlational study. Terapan, 5(2), 260-270.

Hutasuhut, I., Adruce, S. A. Z., \& Jonathan, V. (2021). How a learning organization cultivates selfdirected learning. Journal of Workplace Learning, 33(5), 334-347. https://doi.org/10.1108/JWL05-2020-0074

Jin, N., Line, N. D., \& Yoon, D. (2018). Understanding the role of gratitude in building quality relationships. Journal of Hospitality Marketing \& Management, 27(4), 465-485.

Kardas, F., Zekeriya, C. A. M., Eskisu, M., \& Gelibolu, S. (2019). Gratitude, hope, optimism, and life satisfaction as predictors of psychological well-being. Eurasian Journal of Educational Research, 19(82), 81-100.

Kausar, R. (2018). Relationship between gratitude and happiness in college students. Indian Journal of Positive Psychology, 9(1), 109-113.

Kim, H., \& Qu, H. (2020). The mediating roles of gratitude and obligation to link employees' social exchange relationships and prosocial behavior. International Journal of Contemporary Hospitality Management, 32(2), 644-664. Retrieved from https://doi.org/10.1108/IJCHM-04$\underline{2019-0373}$

Kumari, M. H., \& Madnawat, A. V. S. (2016). Gratitude and forgiveness as a predictor of well-being among female college students. Indian Journal of Positive Psychology, 7(4), 511-514.

Layous, K., \& Lyubomirsky, S. (2014). The how, why, what, when, and who of happiness. Positive Emotion: Integrating the Light Sides and Dark Sides, 473-495.

Loi, N. M., \& Ng, D. H. (2021). The relationship between gratitude, wellbeing, spirituality, and experiencing meaningful work. Psych, 3(2), 85-95.

Lyubomirsky, S., \& Lepper, H. S. (1999). A measure of subjective happiness: Preliminary reliability and construct validation. Social Indicators Research,46(2), 137-155. Retrieved from https://www.jstor.org/stable/27522363

Măirean, C., Turliuc, M. N., \& Arghire, D. (2019). The relationship between trait gratitude and psychological wellbeing in university students: The mediating role of affective state and the moderating role of state gratitude. Journal of Happiness Studies, 20(5), 1359-1377.

McCullough, M. E., Emmons, R. A., \& Tsang, J. (2002). The grateful disposition: A conceptual and empirical topography. Journal of Personality and Social Psychology, 82, 112-127.

Nailah Najwa Zainoodin., Hutasuhut, I. J., Mohamad Azhari Abu Bakar., \& Nurul Wardhani. (2021). Gratitude and its relationship to resilience and academic performance among university students. Journal of Cognitive Sciences and Human Development, 7(2), 57-70.

Rajan, R., \& Easvaradoss, V. (2012). The effect of happiness related to psychological intervention on happiness, forgiveness, and gratitude among adolescents. Indian Journal of Positive Psychology, 3(4), 402-405.

Rash, J. A., Matsuba, M. K., \& Prkachin, K. M. (2011). Gratitude and well-being: Who benefits the most from a gratitude intervention? Applied Psychology: Health and Well-Being, 3(3), 350-369.

Roberts, R. C. (2004). The blessings of gratitude: A conceptual analysis. The Psychology of Gratitude, 58-78.

Robustelli, B. L., \& Whisman, M. A. (2018). Gratitude and life satisfaction in the United States and Japan. Journal of Happiness Studies, 19(1), 41-55. 
Saleem, S., Mahmood, Z., \& Naz, M. (2013). Mental health problems in university students: A prevalence study. FWU Journal of Social Sciences, 7(2), 124-130.

Sapmaz, F., Yıldırım, M., Topçuoğlu, P., Nalbant, D., \& Sızır, U. (2016). Gratitude, forgiveness, and humility as predictors of subjective well-being among university students. International Online Journal of Educational Sciences, 8(1), 38-47.

Seligman, M. E.P. \& Royzman, E. (2003). Authentic happiness. Retrieved from https://www.authentichappiness.sas.upenn.edu/newsletters/authentichappiness/happiness

Sheldon, K. M., Kashdan, T. B., \& Steger, M. F. (Eds.). (2010). Designing positive psychology: Taking stock and moving forward. Oxford University Press.

Sin, N. L., \& Lyubomirsky, S. (2009). Enhancing well-being and alleviating depressive symptoms with positive psychology interventions: A practice-friendly meta-analysis. Journal of Clinical Psychology, 65(5), 467-487.

Singh, B., Salve, S., \& Shejwal, B. R. (2017). Role of gratitude, personality, and psychological wellbeing in happiness among young adults. Indian Journal of Health \& Wellbeing, 8(6), 432-435.

Stoerkel, E. (2020). The science and research on gratitude and happiness. Retrieved from https://positivepsychology.com/gratitude-happiness-research/

Tian, L., Pi, L., Huebner, E. S., \& Du, M. (2016). Gratitude and adolescents' subjective well-being in school: The multiple mediating roles of basic psychological needs satisfaction at school. Frontiers in Psychology, 7, 1-8.

Toepfer, S. M., Cichy, K., \& Peters, P. (2012). Letters of gratitude: Further evidence for author benefits. Journal of Happiness Studies, 13(1), 187-201.

Watkins, P. C., Cruz, L., Holben, H., \& Kolts, R. L. (2008). Taking care of business? Grateful processing of unpleasant memories. The Journal of Positive Psychology, 3(2), 87-99.

Watkins, P. C., Woodward, K., Stone, T., \& Kolts, R. L. (2003). Gratitude and happiness: Development of a measure of gratitude, and relationships with subjective well-being. Social Behavior and Personality: An International Journal, 31(5), 431-451.

Watkins, P.C. (2004). Gratitude and subjective well-being. In R.A. Emmons \& M.E. McCullough (Eds.), The psychology of gratitude (pp. 167-192). New York: Oxford University Press.

Wilson, J. T. (2016). Brightening the mind: The impact of practicing gratitude on focus and resilience in learning. Journal of the Scholarship of Teaching and Learning, 16(4), 1-13.

Wood, A. M., Joseph, S., \& Maltby, J. (2009). Gratitude predicts psychological well-being above the Big Five facets. Personality and Individual Differences, 46(4), 443-447.

Yildirim, M., \& Alanazi, Z. S. (2018). Gratitude and life satisfaction: Mediating role of perceived stress. International Journal of Psychological Studies, 10(3), 21-28.

Yoo J. (2020). Gratitude and subjective well-being among Koreans. International Journal of Environmental Research and Public Health, 17(22), 8467. Retrieved from https://doi.org/10.3390/ijerph17228467

Zivin, K., Eisenberg, D., Gollust, S. E., \& Golberstein, E. (2009). Persistence of mental health problems and needs in a college student population. Journal of Affective Disorders, 117(3), 180185. 